\title{
Different Disease-modifying Treatments do not Affect Quality of Life of Multiple Sclerosis Patients`
}

\section{Fawaz Al-Hussain*}

Department of Neurology, College of Medicine, King Saud University, Riyadh, Saudi Arabia

*Corresponding Author: Fawaz Al-Hussain, Department of Neurology, College of Medicine, King Saud University, Riyadh, Saudi Arabia.
Received: January 06, 2021

Published: February 19, 2021

(C) All rights are reserved by Fawaz

Al-Hussain.

\section{Abstract}

Background: Multiple sclerosis (MS) is a chronic disease of the central nervous system that causes neuronal damage resulting in a variety of symptoms that include pain, fatigue, muscle weakness, impaired balance, and vision loss. In addition to these neurological symptoms patients also experience a decreased quality of life.

Methods: In this study, a cross-sectional analysis was performed to compare the quality of life of MS patients on various treatments including $\beta$-interferon injections, fingolimod oral capsules, and natalizumab intravenous infusion. Quality of life was assessed using the patient-reported EQ-5D-5L assessment. A semi structured question guide was also used to include different research groups from various geographical areas to identify literature study about quality of life and reasons behind their preferences with regard to their treatment and care which was analyzed using content analysis and constructivist approach. Mobility, self-care, participation in usual activities, pain, discomfort, anxiety, and depression were evaluated as predictors of quality of life

Results: All treatments provided a positive impact on the quality of life of MS patients regardless of route of administration.

Conclusions: The percentage of fingolimod treated patients that reported no problems was equal to or greater than the percentage of patients treated with either $\beta$-interferons or natalizumab for each quality of life measurement, demonstrating the benefit of oral treatments on the quality of life of MS patients.

Keywords: Multiple Sclerosis; Quality of Life; Disease-modifying Therapy; Qualitative Research; Decision-Making

\section{Introduction}

Multiple sclerosis (MS) is a chronic progressive autoimmune inflammatory disease that targets myelin components of the central nervous system and is characterized by demyelination and axonal damage resulting in loss of motor and sensory function [1]. Symptoms of MS include pain, fatigue, muscle weakness, impaired balance, and vision loss. The progression of the neurological symptoms associated with MS may involve periodic worsening or relapses [2]. A small percentage of MS cases have a primary progressive course where neurological function steadily declines from the initial onset of symptoms. Most patients experience a relapsingremitting disease course characterized by short periods of relapses followed by quiet periods of remission that can last months or even years. About $85-90 \%$ of MS patients [3] develop a steady progression of symptoms of relapsing-remitting multiple sclerosis (RRMS), with or without periods of remission, known as secondary progressive MS [4].

In addition to the neurological disability experienced by patients, MS also exerts detrimental effects on the quality of life due 
to impaired ability to self-care, decreased mobility, increased discomfort, and inability to partake in usual daily activities [5]. MS patients may face additional hardships such as loss of employment, difficulty in maintaining relationships with other people, and feelings of solitude stemming from the inability to participate in society. A number of studies have shown that the increasing neurologic disability of MS is associated with an impaired quality of life $[6,7]$. As a result, the quality of life experienced by MS patients is significantly lower compared to that of the general population [8]. In addition, MS was reported to be associated with a worse quality of life as compared to patients with other chronic diseases such as diabetes, congestive heart failure, myocardial infarction, hypertension, or depression.

The initial symptoms of MS typically appear during young adulthood, a period of life associated with the struggles of career advancement, starting a family, and caring for dependents [9]. The loss of jobs, lack of social life, impaired mobility, and inability to provide for themselves and their dependents severely impacts the psychological health of young MS patients. So, Quality of life is a broad concept that is affected by multiple parameters other than the patient's health status. These parameters include level of independence, social setting, and psychological state. the assessment of quality of life has been increasingly recognized as an important aspect of MS research [10]. Quality of life in MS patients showed an obvious deterioration as compared to the healthy population.

The quality of life for MS patients can be improved, or at least maintained, if those living with the disease are provided with the means to assure the necessities of life. This can be achieved through financial support, mobility aids, and adequate medical care and treatment [11-13]. Although there is no cure for MS [14].

$\beta$-interferons are injectable medications given subcutaneously or intramuscularly with dosing that can vary from every other day to once a week depending on the of type $\beta$-interferon (Betaferon, Rebif, and Avonex) [15]. Natalizumab is an intravenous medication administered once every four weeks [16]. Fingolimod is an oral capsule taken once per day [17]. The aim of this study is to compare the quality of life of MS patients on various treatments that include either $\beta$-interferon injections, oral treatment, or intravenous infusion treatment. These drugs reduce the number of relapses in large, randomized, controlled trials and given time by approximately one-third [18-21].
Number of Disease-modifying therapies are available for treating MS, but their cost effectiveness is uncertain. It is important to consider the effectiveness and cost-effectiveness of all diseasemodifying medicines to ensure proper MS management.

\section{Materials and Methods}

A large sample of MS patients $(n=452)$ was recruited from 3 participating hospitals located in Riyadh, Saudi Arabia from July 2016 to June 2017. Institutional research boards of all participating hospitals approved this cross-sectional study. Only patients aged 18 years or older, diagnosed with progressive relapsing multiple sclerosis (PRMS), and currently on treatment of either $\beta$-interferon, natalizumab, or fingolimod were included in this study. Patients that experienced MS attacks during the last month or recently switched to a different disease-modifying therapy (DMT) within the last 6 months were excluded from the study. Patients were informed about this study and their consent was obtained prior to proceeding with the questionnaire. Demographic information and treatment history data were collected by telephone interview.

The quality of life of MS patients was determined using the EQ5D-5L a widely-used, standardized measure of health status developed by the EuroQol Group [22]. The first page contains the EQ$5 \mathrm{D}$ descriptive system comprised of the following 5 dimensions: mobility, self-care, usual activities, pain/discomfort and anxiety/ depression. For each dimension the respondent is asked to indicate his/her health state by selecting one of the following levels: no problems, slight problems, moderate problems, severe problems, and extreme problems. The second page contains the EQ Visual Analogue scale which records the respondent's self-rated health. For this study patients were asked to rate their health by selecting a number between 0 (the worst health) and 100 (the best health).

Descriptive statistics such as frequency, percentage, mean and standard deviation (SD) were used to describe and synthesize MS patients' demographic data, illness information, and reported problems for each level for each dimension of EQ-5D. Inferential statistics were then applied to determine differences in MS patients' EQ-5D index value when grouped according to demographic variables (i.e. gender) and illness information (i.e. duration of illness). Independent t-test was utilized to test the significance of differences between nominal variables (i.e. gender) and one-way ANOVA to test significant differences between more than 2 groups 
in interval data (i.e. duration of illness). The Pearson correlation coefficient was used to assess the correlation between the reported EQ-VAS scores and EQ-5D-5L index values. Multiple linear regression was carried out to identify which variables were significantly associated with the quality of life of MS patients (dependent variable). The independent variables were age, sex, duration of illness, and on treatment or not on treatment. The Statistical Package for Social Sciences (SPSS) version 21.0 was used for data analysis. The significance level was predetermined at $\mathrm{p}$-level $<0.05$ for all tests.

Another study was arranged on qualitative focus group interviews with 40 participants invited to participate via the Facebook page of the Canadian MS patient organization. Open ended questions were asked in interview to get insights in participants' current symptoms. The impact of disease on their quality of life i.e. physical, mental, psychosocial, and professional effect were discussed. Finally, participant's treatment experience and preferences regarding disease-modifying therapy were discussed [23]. The interviews were recorded and analyzed with the combination of inductive content analysis. Constructivist approach was used to analyze their social interaction in relation to each patients' personal context $[24,25]$. This framework allowed us to investigate a diversity of statements in a manner that generated clusters of information about patient preferences in MS.

Patients were divided into five focus groups to create confidential setting for discussion among peers with comparable treatment experiences. Group A consisted of recently diagnosed Multiple sclerosis (MS) patients (maximum 18 months). Group B brought together patients diagnosed $>2$ years ago who had switched to another first-line disease-modifying therapy (DMT). In group C, patients had switched to second or later lines of disease-modifying therapy. Group D consisted of patients who were not receiving disease-modifying therapy and group E included patients having opted out of disease-modifying therapy. Besides the varying treatment experiences, the aim was to include a diversity of MS patients with respect to age and gender.

\section{Results}

This study targeted 452 RRMS patients from participating clinics, of which a total of 301 patients were recruited for the final study. The response rate was calculated as $66.6 \%$. Out of the 301 participants 235 patients were on either on interferons, fingolimod, or natalizumab medication. Specifically, 149 used one of the $\beta$-interferons, 58 used fingolimod, and 28 used natalizumab (Table 1). A total of 66 patients recently switched to a different DMT and were excluded from the analyses.

\begin{tabular}{|c|c|c|c|}
\hline Group & \multicolumn{2}{|c|}{ Basic demographic } & Values \\
\hline \multirow{9}{*}{ All patients } & \multicolumn{2}{|c|}{ Total number } & 301 \\
\hline & \multicolumn{2}{|c|}{ Mean age $( \pm S D)$} & $\begin{array}{c}34.38 \\
(10.91)\end{array}$ \\
\hline & \multicolumn{2}{|c|}{ Mean BMI $( \pm$ SD $)$} & $26.12(5.22)$ \\
\hline & \multicolumn{2}{|c|}{ Female gender (\%) } & 207 (68.77) \\
\hline & \multirow{3}{*}{$\begin{array}{c}\text { Marital status } \\
(\%)\end{array}$} & Single & $115(38.21)$ \\
\hline & & Married & $171(56.81)$ \\
\hline & & Others & $15(4.98)$ \\
\hline & \multirow{2}{*}{$\begin{array}{c}\text { Education level } \\
\qquad \%)\end{array}$} & Graduates & $165(54.82)$ \\
\hline & & $\begin{array}{c}\text { Non } \\
\text {-graduates }\end{array}$ & $136(45.18)$ \\
\hline \multirow{4}{*}{ Interferons } & \multicolumn{2}{|c|}{ Total number } & 149 \\
\hline & \multicolumn{2}{|c|}{ Mean age $( \pm S D)$} & $\begin{array}{c}35.69 \\
(12.11)\end{array}$ \\
\hline & \multicolumn{2}{|c|}{ Mean BMI $( \pm$ SD) } & $26.42(5.32)$ \\
\hline & \multicolumn{2}{|c|}{ Female gender (\%) } & $95(63.76)$ \\
\hline \multirow{4}{*}{ Fingolimod } & \multicolumn{2}{|c|}{ Total number } & 58 \\
\hline & \multicolumn{2}{|c|}{ Mean age $( \pm S D)$} & $31.31(7.82)$ \\
\hline & \multicolumn{2}{|c|}{ Mean BMI $( \pm$ SD $)$} & $25.18(3.88)$ \\
\hline & \multicolumn{2}{|c|}{ Female gender (\%) } & 32 (55.17) \\
\hline \multirow{4}{*}{$\begin{array}{l}\text { Natali- } \\
\text { zumab }\end{array}$} & \multicolumn{2}{|c|}{ Total number } & 28 \\
\hline & \multicolumn{2}{|c|}{ Mean age $( \pm S D)$} & $29.53(8.25)$ \\
\hline & \multicolumn{2}{|c|}{ Mean BMI ( \pm SD) } & $25.53(6.13)$ \\
\hline & \multicolumn{2}{|c|}{ Female gender (\%) } & $20(71.43)$ \\
\hline
\end{tabular}

Table 1: Baseline characteristics of multiple sclerosis patients participating in study.

The EQ-5D-5L standardized measure of health status was used in this study to assess the quality of life of the participating MS patients. When asked about their mobility, 59,60 , and $43 \%$ of patients on $\beta$-interferons, fingolimod, and natalizumab treatment, respectively, reported no issues with walking about. The majority of patients on any of the DMTs were able to self-care ( $\geq 68 \%$ ), with very few patients reporting that they were unable to wash or dress themselves $(\leq 5 \%)$. Similarly, the majority of patients on any DMT could perform usual activities (55\%) and reported no discomfort 
(59\%). More than $56 \%$ of patients who were on any of the DMTs were neither anxious nor depressed (Table 2). The percentage of patients that were able to move, self-care, perform usual activities, and not feel discomfort nor depression was comparable for each form of DMT. The percentage of fingolimod treated patients report- ing no problems for each of the 5 dimensions was equal to or greater than the percentage of patients treated with either $\beta$-interferons or natalizumab, thus demonstrating the positive impact of oral treatment on quality of life of MS patients.

\begin{tabular}{|c|c|c|c|c|c|}
\hline \multirow{2}{*}{ Variables } & \multirow{2}{*}{ Groups } & \multicolumn{4}{|c|}{ Total number (\%) } \\
\hline & & Interferons & Fingolimod & Natalizumab & All DMTs \\
\hline \multirow{5}{*}{ Mobility } & I have no problems walking about & $88(59)$ & $35(60)$ & $12(43)$ & $135(57)$ \\
\hline & I have slight problems walking about & $22(15)$ & $7(12)$ & $7(25)$ & $36(15)$ \\
\hline & I have moderate problems walking about & $21(14)$ & $6(10)$ & $5(18)$ & $32(14)$ \\
\hline & I have severe problems walking about & $10(7)$ & $7(12)$ & $1(4)$ & $18(8)$ \\
\hline & I am unable to walk about & $8(5)$ & $3(5)$ & $3(11)$ & $14(6)$ \\
\hline \multirow{5}{*}{ Self-care } & I have no problems washing or dressing myself & $107(72)$ & $44(76)$ & $9(68)$ & $170(72)$ \\
\hline & I have slight problems washing or dressing myself & $25(17)$ & $6(10)$ & $6(21)$ & $37(16)$ \\
\hline & $\begin{array}{l}\text { I have moderate problems washing or dressing } \\
\text { myself }\end{array}$ & $8(5)$ & $4(7)$ & $1(4)$ & $13(6)$ \\
\hline & $\begin{array}{l}\text { I have severe problems washing or dressing } \\
\text { myself }\end{array}$ & $1(1)$ & $1(2)$ & $1(4)$ & $3(1)$ \\
\hline & I am unable to wash or dress myself & $8(5)$ & $3(5)$ & $1(4)$ & $12(5)$ \\
\hline \multirow{5}{*}{$\begin{array}{l}\text { Usual } \\
\text { activities }\end{array}$} & I have no problems doing my usual activities & $79(53)$ & $37(64)$ & $13(46)$ & $129(55)$ \\
\hline & I have slight problems doing my usual activities & $30(20)$ & $9(16)$ & $7(25)$ & $46(20)$ \\
\hline & $\begin{array}{l}\text { I have moderate problems doing my usual } \\
\text { activities }\end{array}$ & $23(15)$ & $8(14)$ & $5(18)$ & $36(15)$ \\
\hline & I have severe problems doing my usual activities & $4(3)$ & $1(2)$ & $1(4)$ & $6(3)$ \\
\hline & I am unable to do my usual activities & $13(9)$ & $3(5)$ & $2(7)$ & $18(8)$ \\
\hline \multirow{5}{*}{$\begin{array}{l}\text { Pain/ } \\
\text { Discomfort }\end{array}$} & I have no pain or discomfort & $90(60)$ & $35(60)$ & $14(50)$ & $139(59)$ \\
\hline & I have slight pain or discomfort & $26(17)$ & $11(19)$ & $7(25)$ & $44(19)$ \\
\hline & I have moderate pain or discomfort & $27(18)$ & $6(10)$ & $3(11)$ & $36(15)$ \\
\hline & I have severe pain or discomfort & $5(3)$ & $4(7)$ & $2(7)$ & $11(5)$ \\
\hline & I have extreme pain or discomfort & $1(1)$ & $2(3)$ & $2(7)$ & $5(2)$ \\
\hline \multirow{5}{*}{$\begin{array}{l}\text { Anxiety/ } \\
\text { Depression }\end{array}$} & I am not anxious or depressed & $83(56)$ & $33(57)$ & $16(57)$ & $132(56)$ \\
\hline & I am slightly anxious or depressed & $41(28)$ & $14(24)$ & $7(25)$ & $62(26)$ \\
\hline & I am moderately anxious or depressed & $18(12)$ & $8(14)$ & $4(14)$ & $30(13)$ \\
\hline & I am severely anxious or depressed & $5(3)$ & $2(13)$ & $1(4)$ & $8(3)$ \\
\hline & I am extremely anxious or depressed & $2(1)$ & $1(2)$ & $0(0)$ & $3(1)$ \\
\hline
\end{tabular}

Table 2: Quality of life of patients treated with interferons, fingolimod, and natalizumab.

The health status of MS patients was determined by the selfreported health scores from the EQ Visual Analogue scale ranging from the best and the worst health condition. The health scores of MS patients who were on $\beta$-interferons, fingolimod, and natali- 
zumab treatment were $72.7(\mathrm{SD}=19.6), 68.2(\mathrm{SD}=18.8)$, and 67.3 $(\mathrm{SD}=18.2$ ), respectively (Table 3 ). The comparable health score between different treatment groups depicts similar effects of different DMTs on the quality of life of MS patients.

\begin{tabular}{|l|c|c|c|}
\hline \multicolumn{1}{|c|}{ DMTs } & $\begin{array}{c}\text { Total } \\
\text { number }\end{array}$ & Score \pm SD & P value (ANOVA) \\
\hline Interferons & 149 & $72.7 \pm 19.6$ & \multirow{2}{*}{0.183} \\
\hline Fingolimod & 58 & $68.2 \pm 18.8$ & \\
\hline Natalizumab & 28 & $67.3 \pm 18.2$ & \\
\hline \multicolumn{2}{|l}{ DMTs, disease-modifying therapies } \\
\hline
\end{tabular}

Table 3: Health score on scale.

Study of focus groups was conducted among 40 participants in which 29 were women and 11 men, aged between 18 to 63 years. Selected participants had been diagnosed between 2 months and 28 years ago. They attended 12 different hospitals across Canada whom of which 36 participants received 11 different types of DMT.

The following four main topics were discussed in the interview:

- Quality of life impact of MS: MS diagnosis had given distress, worries fatigue, recurring emotional oversensitivity, depression, anxiety, and anger to most of the participants for 2-3 years. Discussion revealed that MS diagnosis changed participant's self-perception of having psychosocial quality of life.

- Treatment experiences: Treatment related issues highly influenced the participant's quality of life and disease experience. Participant's reason of opting out of DMT was mainly due to side effects. Despite consequent relapses, they felt that their present quality of life was more important than the risk of disease progression. But they didn't entirely reject the of opting for DMT again. Participants with a shorter time since diagnosis were less actively involved in DMT decision making and preferred leaving the choice of DMT to the neurologist. Participants with longer time since diagnosis were more involved in treatment decision and less accepting of side effects.

- The participants' treatment preferences: The participants' treatment preferences were depended on efficacy, side effects, and mode of administration. Some had fear of needles leading to them reject any type of injectable DMT; others opted for the monthly natalizumab infusions due to its lack of daily administration and side effects.

- Additional care and support needs: The final main topic was related to the participants' non-medical needs for care and support. The initial fear of disability, destabilized identity, and avoidance of other MS patients led them to delaying the contact when support was needed. The participants expressed an unmet support need at the time of diagnosis, which they preferred be met by the neurology clinics.

\section{Discussion}

The current knowledge about the quality of life experienced by MS patients is limited. As such, a consistent and reliable measure of health-related quality of life is needed to facilitate the research evaluating clinical effectiveness and quality of care for multiple sclerosis patients.

This study employed the EQ-5D-5L system to assess a measure of quality of life of MS patients on various treatments that included $\beta$-interferon injections, fingolimod oral treatment, and natalizumab intravenous infusion.

Fingolimod treated patients reported less problems for all 5 dimensions of the EQ-5D descriptive system compared to the other DMTs, demonstrating the positive impact of oral treatment on the quality of life of MS patients. This may be due to the lower amount of stress associated with taking an oral capsule compared to $\beta$-interferon injections and the intravenous delivery of natalizumab. This notion is supported by results from a previous crosssectional study of MS patients that showed mild anxiety was higher among interferon users, a finding that was likely due to the anxiety associated with injections [26].

The self-reported health status, as determined by the EQ Visual Analogue scale, was comparable for all MS patients regardless of their DMT. This demonstrates that different DMTs have a similar positive impact on the quality of life of MS patients regardless of route of administration. Although it is a very simple questionnaire, its design does not negatively affect its usefulness and reliability. There are other questionnaires that are available in Arabic such as the MusiQoL and the SF-36. The Middle East MS Advisory Group recommends routine assessments of quality of life using the $\mathrm{Mu}$ siQoL and the SF-36 in addition to other supplementary information [27]. 
Quality of life is a broad concept that is affected by multiple parameters other than the patient's health status. These parameters include level of independence, social setting, and psychological state. The assessment of quality of life has been increasingly recognized as an important aspect of MS research [28]. Several studies reported in the literature regarding quality of life in MS patients as compared to patients with other chronic diseases such as diabetes, congestive heart failure, myocardial infarction, hypertension, or depression [29]. Depression and loss of cognitive function usually affect the employment status and social functioning of the patient. These 2 symptoms were reported by patients with MS as important determinants of their quality of life, and some patients believe that these symptoms are more important than their physical impairments.

The use of disease modifying drugs has been reported to affect the quality of life. The variability of the results may be due to the availability of a variety of medications with variable side effects. The frequent self-injection with its associated side effects including injection-site reactions and flu-like symptoms may negatively impact the quality of life. Another important point to be illustrated is that the benefits of these medications may not be obvious to patients which may lead to low adherence and further relapses that will also affect the quality of life negatively [30].

Qualitative explorations of MS patients' reflections on the tradeoffs of DMT administration, risks of side effects, and efficacy have been lacking. This study aimed to examine how MS patients' disease experiences and quality of life might explain and relate to their treatment preferences and support needs.

\section{Conclusion}

The findings from this study provide evidence that the quality of life can be reliably measured for MS patients on different DMTs. The recording of such measurements may prove valuable for future assessments of quality of life during the treatment of MS and will be beneficial for evaluating the effectiveness of various interventions.

Declaration

Consent for Publication

Not applicable.

\section{Ethics Approval and Consent to Participate}

The protocol of research was reviewed and approved by the Ethics and Research Committee of the King Saud University and written consent was obtained from all participants before starting the procedure. For the other study patients were encouraged to give subjective description of their disease experience and their treatment preferences that is why study did not require ethics committee approval of Canada.

\section{Availability of Data and Material}

All data are included in the manuscript. However, the datasets used and/or analyzed during the current study are available from the corresponding author on reasonable request.

\section{Competing Interests}

The author(s) declare(s) that there is no conflict of interest regarding the publication of this paper.

\section{Funding}

The authors extend their appreciation to the Deanship of Scientific Research at King Saud University for funding this work through research group No (RG- 1438-089).

\section{Acknowledgements}

The authors extend their appreciation to the participants did the study.

\section{Bibliography}

1. Compston A and Coles A. "Multiple sclerosis". The Lancet 372.9648 (2008): 1502-1517.

2. Lublin FD and Reingold SC. "Defining the clinical course of multiple sclerosis: results of an international survey. National Multiple Sclerosis Society (USA) Advisory Committee on Clinical Trials of New Agents in Multiple Sclerosis". Neurology 46.4 (1996): 907-911.

3. McKay KA., et al. "Risk factors associated with the onset of relapsing-remitting and primary progressive multiple sclerosis: a systematic review". BioMed Research International 2015 (2015): 817238.

4. Lublin FD., et al. "Defining the clinical course of multiple sclerosis: the 2013 revisions". Neurology 83.3 (2014): 278-286. 
5. Salter AR., et al. "Impact of loss of mobility on instrumental activities of daily living and socioeconomic status in patients with MS". Current Medical Research and Opinion 26.2 (2010): 493-500.

6. Janardhan V and Bakshi R. "Quality of life and its relationship to brain lesions and atrophy on magnetic resonance images in 60 patients with multiple sclerosis". Archives of Neurology 57.10 (2000): 1485-1491.

7. Nortvedt MW., et al. "Quality of life in multiple sclerosis: measuring the disease effects more broadly". Neurology 53.5 (1999): 1098-1103.

8. Vickrey BG., et al. "A health-related quality of life measure for multiple sclerosis". Quality of Life Research 4.3 (1995): 187206.

9. Milo R and Kahana E. "Multiple sclerosis: geoepidemiology, genetics and the environment". Autoimmunity Reviews 9.5 (2010): A387-394.

10. Zwibel HL. "Contribution of impaired mobility and general symptoms to the burden of multiple sclerosis". Advances in Therapy 26.12 (2009): 1043-1057.

11. Casado V., et al. "Direct and indirect costs of Multiple Sclerosis in Baix Llobregat (Catalonia, Spain), according to disability". BMC Health Services Research 6 (2006): 143.

12. Ertekin Ö., et al. "Caregiver burden, quality of life and walking ability in different disability levels of multiple sclerosis". Neuro Rehabilitation 34.2 (2014): 313-321.

13. Parisé H., et al. "Direct and indirect cost burden associated with multiple sclerosis relapses: excess costs of persons with MS and their spouse caregivers". Journal of the Neurological Sciences 330 (2013): 71-77.

14. Gajofatto A and Benedetti MD. "Treatment strategies for multiple sclerosis: When to start, when to change, when to stop?" World Journal of Clinical Cases 3.7 (2015): 545-555.

15. Etemadifar M., et al. "Comparison of Betaferon, Avonex, and Rebif in treatment of relapsing-remitting multiple sclerosis". Acta Neurologica Scandinavica 113.5 (2006): 283-287.
16. Miller DH., et al. "A controlled trial of natalizumab for relapsing multiple sclerosis". The New England Journal of Medicine 348.1 (2003): 15-23.

17. Kappos L., et al. "A placebo-controlled trial of oral fingolimod in relapsing multiple sclerosis". The New England Journal of Medicine 362.5 (2010): 387-401.

18. The IFNB Multiple Sclerosis Study Group and The University of British Columbia MS/MRI Analysis Group. "Interferon beta-1b in the treatment of multiple sclerosis: final outcome of the randomized controlled trial". Neurology 45 (1995): 127785.

19. Jacobs LD., et al. "Intramuscular interferon beta-1a for disease progression in relapsing multiple sclerosis. The Multiple Sclerosis Collaborative Research Group (MSCRG)". Annals of Neurology 39 (1996): 28594.

20. PRISMS (Prevention of Relapses and Disability by Interferon beta-1a Subcutaneously in Multiple Sclerosis) Study Group. "Randomised double-blind placebo-controlled study of interferon beta-1a in relapsing/remitting multiple sclerosis". Lancet 352 (1998): 1498504.

21. Johnson KP., et al. "Copolymer 1 reduces relapse rate and improves disability in relapsing-remitting multiple sclerosis: results of a phase III multicenter, double-blind placebo-controlled trial. The Copolymer 1 Multiple Sclerosis Study Group". Neurology 45 (1995): 126876.

22. Herdman M., et al. "Development and preliminary testing of the new five-level version of EQ-5D (EQ-5D-5L)". Quality of Life Research 20.10 (2011): 1727-1736.

23. Halkier B. Fokusgrupper. Frederiksberg: Samfundslitteratur and Roskilde Universitetsforlag (2002).

24. Elo S and Kyngäs H. "The qualitative content analysis". Journal of Advanced Nursing 62 (2008): 107-115.

25. Winther Jørgensen M and Phillips L. "Diskursanalyse som teori og metode”. Roskilde: Roskilde University Press (1999).

26. Al-Hussain F., et al. "Depression, anxiety and stress severities in multiple sclerosis patients using injectable versus oral treatments". Journal of Comparative Effectiveness Research 6.5 (2017): 405-412. 
27. Al-Tahan AM., et al. "The importance of quality-of-life assessment in the management of patients with multiple sclerosis. Recommendations from the Middle East MS Advisory Group". Neurosciences (Riyadh) 16 (2011): 109-113.

28. Kes VB., et al. "Quality of life in patients with multiple sclerosis". Acta Clinica Croatica 52 (2013): 107-111.

29. Göksel karatepe A., et al. "Quality of life in patients with multiple sclerosis: the impact of depression, fatigue, and disability". International Journal of Rehabilitation Research 34 (2011): 290-298.

30. Lily O., et al. "Disease-specific quality of life in multiple sclerosis: the effect of disease modifying treatment". Multiple Sclerosis Journal 12 (2006): 808-813.

\section{Assets from publication with us}

- Prompt Acknowledgement after receiving the article

- Thorough Double blinded peer review

- Rapid Publication

- Issue of Publication Certificate

- High visibility of your Published work

Website: www.actascientific.com/

Submit Article: www.actascientific.com/submission.php

Email us: editor@actascientific.com

Contact us: +919182824667 